REVISTA

\title{
PROPOSTA DE PLANO DE GERENCIAMENTO DE RESÍDUOS SÓLIDOS (PGRS) EM UM POSTO COMBUSTÍVEL NA CIDADE DE SÃO MATEUS, ES
}

\author{
PROPOSED SOLID WASTE MANAGEMENT PLAN (SWMP): AT A FUEL \\ STATION IN THE SÃO MATEUS CITY, ES
}

\author{
Jociane Liandro Rezeno ${ }^{1 *}$ \\ Cristiane Alves da Silva do Nascimento ${ }^{2}$ \\ ${ }^{1}$ Instituto Federal do Espírito Santo. E-mail: jocianerezeno@gmail.com. \\ ${ }^{2}$ Faculdade Multivix. E-mail: crisalves.bio@gmail.com. \\ Autor para correspondência: E-mail: jocianerezeno@gmail.com.
}

Artigo submetido em 29/10/2019, aceito em 12/12/2019 e publicado em 23/12/2019.

Resumo: O presente estudo propõe um Plano de Gerenciamento de Resíduos Sólidos para um posto combustível no município de São Mateus, ES, levando em consideração que os resíduos gerados em postos combustíveis, em sua maioria, podem ser reaproveitados e seus impactos podem ser controlados ou evitados, além de evitar problemas ambientais, ao aplicar um sistema de gestão ambiental. Com o levantamento dos resíduos gerados, verificou-se que o empreendimento gera resíduos recicláveis, orgânicos, rejeitos sanitários e resíduos perigosos. Os resíduos recicláveis não são segregados corretamente e são armazenados juntamente com os orgânicos e rejeitos em sacos plásticos e coletados pela prefeitura que, posteriormente, são encaminhados para um aterro sanitário. Os resíduos perigosos são armazenados em tambores e coletados por empresas especializadas. Apesar de já adotar algumas medidas adequadas, o estudo verificou que o empreendimento precisa de melhorias em sua gestão de resíduos sólidos e as propôs. Para o sucesso do plano de gerenciamento, a colaboração dos funcionários é fundamental.

Palavras-chave: posto combustível; plano de gerenciamento; resíduos sólidos.

\begin{abstract}
The present study proposes a Solid Waste Management Plan for a fuel station in the county of São Mateus, ES, taking into account that the waste generated in fuel stations, for the most part, can be reused and its impacts can be controlled or avoided, as well as avoiding environmental problems, by applying an environmental management system. With the survey of the generated waste, it was verified that the enterprise generates recyclable, organic waste, sanitary waste and hazardous waste. Recyclable waste is not properly segregated and is stored together with organic and tailings in plastic bags and collected by the city, which is then sent to a landfill. Hazardous waste is stored in drums and collected by specialized companies. Despite already taking some appropriate measures, the study verified that the enterprise needs improvements in its solid waste management and proposed them. For the success of the management plan, employee collaboration is critical.
\end{abstract}

Keywords: fuel station; management plan; solid waste. 


\section{INTRODUÇÃO}

O desenvolvimento econômico e a revolução tecnológica ao longo dos anos vêm modificando os modos de produção e consumo da população, resultando em aumento na geração de resíduos urbanos, que possuem compostos perigosos e prejudiciais ao meio ambiente e à saúde humana (GOUVEIA, 2012).

Os impactos causados pelos resíduos das atividades comerciais, como postos de combustíveis, têm se tornado preocupantes, principalmente devido a instalação e armazenamento de combustíveis potencialmente ou parcialmente poluidores e geradores de acidentes ambientais, como vazamento de combustíveis, que podem causar contaminação de corpos d'água subterrâneos e superficiais, do solo e do ar, além de riscos de incêndios e explosões; dentre outros (CONAMA, 2000).

De acordo com Santos (2005), os impactos causados pelos resíduos gerados por postos de combustíveis podem ser controlados ou evitados, obstando-se também problemas ambientais, quando se aplica um sistema de gestão ambiental.

Diante desse cenário, uma grande conquista foi a criação da Política Nacional de Resíduos Sólidos que dispõe, entre outras providências, as diretrizes relativas à gestão integrada e ao gerenciamento de resíduos sólidos, incluindo os perigosos (BRASIL, 2010).

Uma maneira eficiente de gerir os resíduos sólidos de um empreendimento contribui para a redução não somente dos problemas ambientais, mas também dos gastos com materiais utilizados, gerando ao empreendimento uma economia significativa.

\section{REFERENCIAL TEÓRICO}

2.1 Resíduos gerados em postos de combustíveis
Os resíduos sólidos de postos de combustíveis podem, em sua maioria, ser reaproveitados. Esses resíduos, quando descartados de forma inadequada ocasionam uma série de doenças aos seres humanos. Os principais vetores associados à transmissão de doenças por meio do lixo são moscas, baratas, mosquitos e roedores, podendo transmitir febre tifóide, amebíase, dengue e leptospirose (FUNASA, 2013).

Dentre os diversos resíduos gerados em um posto de combustível, destacam-se: embalagens de papelão, óleo lubrificante e suas embalagens plásticas e metálicas, garrafas PET, filtros de óleo, de ar e de combustível, panos e estopas usadas contaminados com óleo e outros combustíveis (COSTA \& FERREIRA, 2008). Ainda segundo os autores, cerca de $85 \%$ dos postos possuem troca de óleo, cujas embalagens plásticas apresentam benzeno, um produto químico nocivo à saúde humana e ao meio ambiente.

\subsection{Classificação dos resíduos}

Segundo a NBR 10004/2004, os resíduos sólidos são classificados, quanto à periculosidade, da seguinte forma:

Resíduos classe I - Perigosos: Apresentam risco a saúde pública e ao meio ambiente. São inflamáveis, corrosivos, reativos, tóxicos e patogênicos. São exemplos, latas de tinta, óleos lubrificantes e suas embalagens, lodo da rampa de lavagem, filtros de óleo.

Resíduos classe II A - Não perigosos e não inertes: Podem apresentar propriedades como biodegradabilidade, combustibilidade e solubilidade em água, por exemplo, papel, plástico, resíduos orgânicos.

Resíduos classe II B - Não perigosos e inertes: São aqueles que ao entrarem em contato com a água, não tem nenhum de seus constituintes solubilizados a 
concentrações superiores aos padrões de potabilidade de água, por exemplo, madeira, areia, entulho de demolição.

\subsection{Logística reversa}

De acordo com a Política Nacional de Resíduos Sólidos, no seu artigo 3, a logística reversa é definida como:

Instrumento de desenvolvimento
econômico e social caracterizado por
um conjunto de ações, procedimentos
e meios destinados a viabilizar a coleta
e a restituição dos resíduos sólidos ao
setor empresarial, para
reaproveitamento, em seu ciclo ou em
outros ciclos produtivos, ou outra
destinação final ambientalmente
adequada.

Desta forma, os comerciantes ou distribuidores deverão efetuar, após o uso pelo consumidor, a devolução dos produtos e embalagens aos fabricantes ou importadores, tais como: agrotóxicos e seus resíduos e embalagens, pilhas e baterias, pneus, óleos lubrificantes, seus resíduos e embalagens, lâmpadas fluorescentes, produtos eletroeletrônicos e seus componentes (BRASIL, 2010).

\subsection{Legislação ambiental}

No Brasil, o principal instrumento da legislação, referente aos resíduos sólidos urbanos, é a Política Nacional dos Resíduos Sólidos (PNRS), Lei 12.305 de 02 de agosto de 2010.

No Estado do Espírito Santo, a Lei 9.264 de 15 de julho de 2009 institui a Política Estadual de Resíduos Sólidos e define, dentre outras providências, diretrizes para a redução, o reaproveitamento e o gerenciamento adequado dos resíduos sólidos, assegurando o uso adequado dos recursos ambientais no estado.

Em relação a legislação para comércio varejista de combustível, a Resolução 273 do Conselho Nacional do Meio Ambiente - CONAMA de 29 de novembro de 2000, estabelece diretrizes para o licenciamento ambiental de postos de combustíveis e serviços e dispõe sobre a prevenção e controle da poluição.

3.5 Plano de gerenciamento de resíduos sólidos

O Plano de Gerenciamento de Resíduos Sólidos (PGRS) engloba a gestão desde a geração do resíduo até a sua disposição final.

O artigo 21 da Lei 12.305/2010 prevê um conteúdo mínimo para o plano de gerenciamento de resíduos sólidos, compreendendo desde a descrição do empreendimento, passando pelo diagnóstico dos resíduos gerados, identificação das soluções, ações preventivas e corretivas, metas para minimização da geração, reutilização e reciclagem dos resíduos, medidas saneadoras dos passivos ambientais, até a revisão periódica do plano de gerenciamento.

\section{PROCESSOS METODOLÓGICOS}

\subsection{Caracterização do empreendimento}

$\mathrm{O}$ empreendimento localiza-se às margens da Rodovia BR 101 - Norte, no município de São Mateus, litoral norte do Espírito Santo (Figura 1). A empresa tratase de um posto combustível, com atividades que consistem em armazenamento e abastecimento com gasolina comum e aditivada, verificação de óleo, calibragem de pneus, lavagem de para-brisas durante o abastecimento e serviços administrativos. A pista de abastecimento funciona 24 horas e o escritório de segunda a sexta-feira, das 8:00h às 17:00h. Ao todo, o local dispõe de oito funcionários.

$\mathrm{O}$ posto contém duas bombas automáticas com total de 6 bicos e dois tanques com capacidade para 30 mil litros cada. Por mês, são comercializados aproximadamente 240 litros de gasolina, entre comum e aditivada, e 28 litros de óleo lubrificante. 
Figura 1: Mapa da localização do município de São Mateus, ES

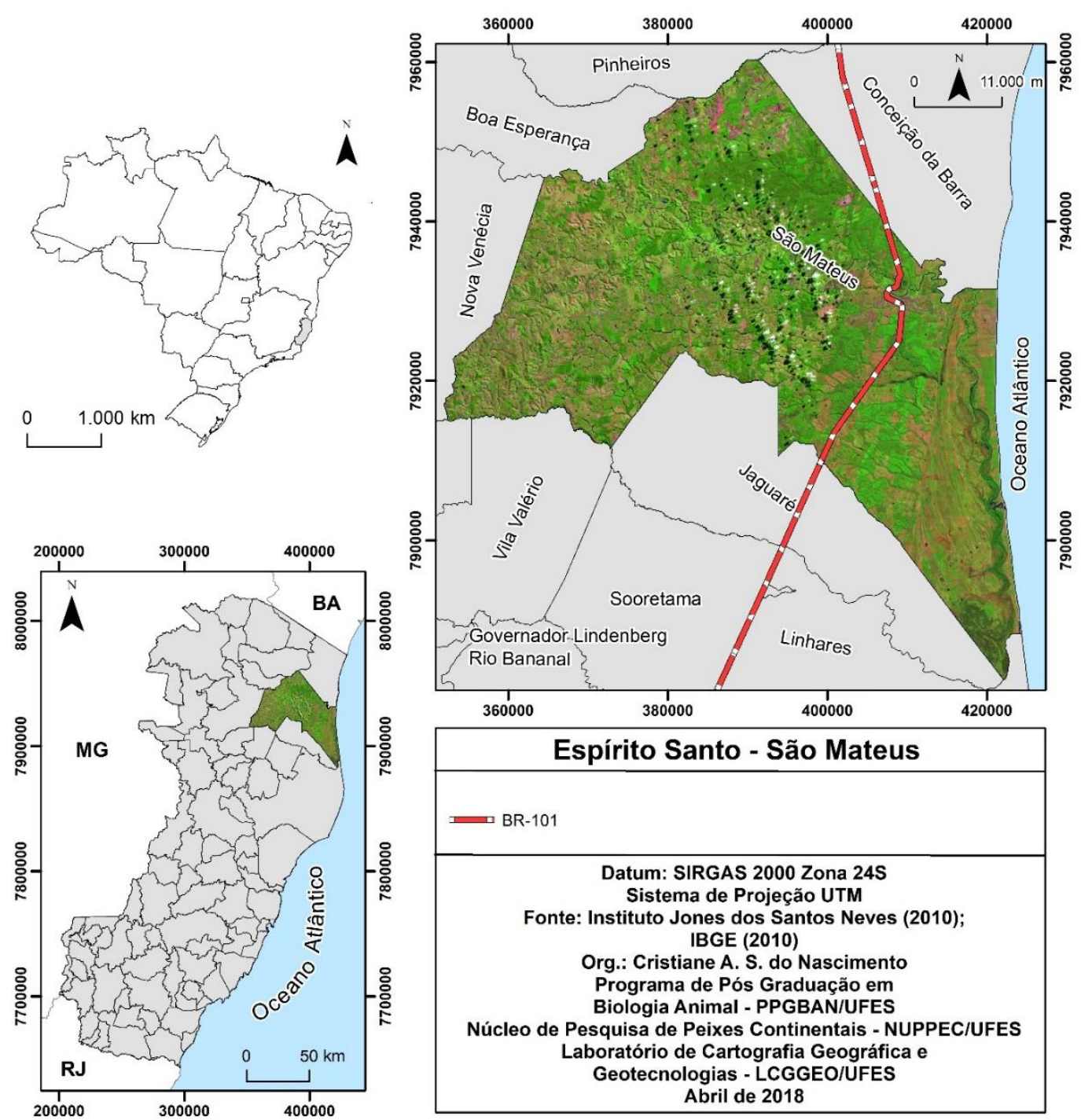

Fonte: IJSN (2010); IBGE (2010).

\subsection{Procedimentos de campo}

Para obter os dados referentes ao gerenciamento atual de resíduos sólidos e ao funcionamento do posto combustível, a gerente responsável pelo empreendimento foi solicitada para fornecer todas as informações necessárias.

O levantamento dos resíduos gerados foi realizado entre os dias 1 e 7 de fevereiro de 2018, no próprio espaço. Para isso, os resíduos foram coletados e segregados de acordo com sua natureza, com o auxílio de luvas descartáveis e acondicionados em sacos plásticos. Após a

segregação, os resíduos foram pesados com a utilização de uma balança eletrônica

Dahongying, com capacidade para 40 quilos.

Dessa forma, foi possível realizar o diagnóstico da situação atual do empreendimento. Para minimizar os problemas encontrados, foram propostas atividades de gerenciamento adequadas dos 
resíduos, verificando as possibilidades de melhoria do sistema.

Para demonstrar a importância da correta gestão dos resíduos sólidos, facilitando possíveis mudanças futuramente, foi realizada uma rápida educação ambiental com os funcionários do posto combustível.

\subsection{Elaboração do PGRS}

A elaboração do PGRS para o presente empreendimento foi baseada no conteúdo mínimo e na ordem de prioridade definidos pela Lei $n^{\circ} 12.305 / 2010$, no seu artigo 21 .

\section{RESULTADOS E DISCUSSÃO}

\subsection{GERAÇÃO DE RESÍDUOS}

Durante a semana de coleta de dados, o empreendimento gerou 24,5 quilos de resíduos sólidos, entre materiais orgânicos, estopas e outros tecidos contaminadas, rejeitos sanitários e resíduos recicláveis. Também foram contabilizados, durante o período de execução do trabalho, 16 unidades de embalagens plásticas contaminadas com óleo e aproximadamente 15 litros de lodo proveniente da caixa separadora.

\subsection{Inventário}

Os locais de geração de resíduos no empreendimento compreendem a pista de abastecimento, escritório, área de alimentação dos funcionários e banheiros. $\mathrm{O}$ Quadro 1 apresenta o levantamento da situação atual do posto.

Com a elaboração do inventário pode-se identificar as fontes geradoras de resíduo, a quantidade de resíduo circulando no sistema e sua destinação, além de determinar a poluição associada a um ponto e identificar desperdício de matéria prima ou de produção de resíduos (GIANNETTI, ET AL., 2003).

Quadro 1: Diagnóstico atual do empreendimento

\begin{tabular}{|c|c|c|c|c|}
\hline Resíduo gerado & $\begin{array}{l}\text { Classificaçãa } \\
\text { do resíduo }\end{array}$ & Fonte geradora & $\begin{array}{l}\text { Quantidade } \\
\text { gerada durante } \\
\text { a coleta de } \\
\text { dados }\end{array}$ & Destinação final \\
\hline $\begin{array}{l}\text { Papel A4, papel } \\
\text { toalha }\end{array}$ & $\begin{array}{l}\text { Classe II-A } \\
\text { não inerte }\end{array}$ & $\begin{array}{l}\text { Escritório, área } \\
\text { de alimentação }\end{array}$ & $10,162 \mathrm{~kg}$ & $\begin{array}{l}\text { Coleta pela limpeza } \\
\text { pública municipal }\end{array}$ \\
\hline Plásticos diversos & $\begin{array}{l}\text { Classe II-A } \\
\text { não inerte }\end{array}$ & $\begin{array}{l}\text { Escritório, área } \\
\text { de alimentação }\end{array}$ & $3,326 \mathrm{~kg}$ & $\begin{array}{l}\text { Coleta pela limpeza } \\
\text { pública municipal }\end{array}$ \\
\hline Rejeitos sanitários & $\begin{array}{l}\text { Classe II-A } \\
\text { não inerte }\end{array}$ & Banheiros & $2,205 \mathrm{~kg}$ & $\begin{array}{l}\text { Coleta pela limpeza } \\
\text { pública municipal }\end{array}$ \\
\hline $\begin{array}{c}\text { Estopas } \\
\text { contaminadas }\end{array}$ & $\begin{array}{l}\text { Classe I } \\
\text { perigoso }\end{array}$ & $\begin{array}{c}\text { Pista de } \\
\text { abastecimento }\end{array}$ & $2,055 \mathrm{~kg}$ & $\begin{array}{c}\text { Coleta por empresa } \\
\text { especializada em resíduos } \\
\text { perigosos }\end{array}$ \\
\hline Orgânicos & $\begin{array}{l}\text { Classe II-A } \\
\text { não inerte }\end{array}$ & $\begin{array}{l}\text { Área de } \\
\text { alimentação }\end{array}$ & $6,704 \mathrm{~kg}$ & $\begin{array}{l}\text { Coleta pela limpeza } \\
\text { pública municipal }\end{array}$ \\
\hline $\begin{array}{l}\text { Embalagens de } \\
\text { óleo }\end{array}$ & $\begin{array}{l}\text { Classe I } \\
\text { perigoso }\end{array}$ & $\begin{array}{c}\text { Pista de } \\
\text { abastecimento }\end{array}$ & 16 unidades & $\begin{array}{c}\text { Coleta por empresa } \\
\text { especializada em logística } \\
\text { reversa }\end{array}$ \\
\hline $\begin{array}{l}\text { Lodo da caixa } \\
\text { separadora }\end{array}$ & $\begin{array}{l}\text { Classe I } \\
\text { perigoso }\end{array}$ & $\begin{array}{c}\text { Pista de } \\
\text { abastecimento }\end{array}$ & $15 \mathrm{~L}$ & $\begin{array}{c}\text { Coleta por empresa } \\
\text { especializada em resíduos } \\
\text { perigosos }\end{array}$ \\
\hline
\end{tabular}

Fonte: autoria própria. 


\subsection{Segregação, acondicionamento e coleta}

Os resíduos perigosos são armazenados em tambores de 200 litros e coletados a cada dois meses. Os resíduos das caixas separadoras ao redor da pista de abastecimento e as estopas utilizadas na verificação do nível de óleo nos veículos são recolhidos por empresa especializada, que realiza a disposição final adequada desses resíduos. A forma de gestão utilizada pela empresa está de acordo com o que dizem Lorenzett \& Rossato (2010), que comentam que no tratamento realizado na caixa separadora de água e óleo, são removidos os resíduos de combustíveis e lubrificantes da água, restando no final do processo um lodo tóxico, impróprio para reutilização, que deverá ser recolhido por uma empresa especializada, para fazer a disposição correta.

As embalagens plásticas contaminadas com óleo, após o uso, são recolhidas por empresa especializada em logística reversa, estando de acordo com o que está definido na PNRS, em seu artigo 33, que diz que os óleos lubrificantes, suas embalagens e resíduos, são objeto de logística reversa obrigatória.

Levando em consideração que a logística reversa consiste em retornar para o fornecedor seus produtos, resíduos ou sucatas para reciclagem ou reuso, pode-se dizer que ela é de suma importância para o gerenciamento de resíduos, pois quando descartados após a utilização, os bens farão parte da cadeia de pós-consumo, onde poderão ser reciclados, reutilizados ou, dependendo de suas condições, dispostos em aterros sanitários (LORENZETT \& ROSSATO, 2010).

Os resíduos recicláveis gerados não são segregados e acondicionados corretamente, sendo armazenados juntamente com resíduos orgânicos e rejeitos sanitários, em um saco plástico. De acordo com Silva \& Carvalho (2011), os resíduos contaminados pela matéria orgânica não possuem valor econômico, entretanto, se cada componente for adequadamente separado, esses resíduos podem ser reaproveitados, reciclados e gerar renda.

Todos esses resíduos são coletados pela empresa de limpeza pública municipal e, posteriormente, são encaminhados para um aterro sanitário no município de Aracruz, localizado a 140 quilômetros de São Mateus.

4.4 Melhorias no gerenciamento de resíduos sólidos

Para a melhoria do gerenciamento dos resíduos sólidos é adequado adotar, primeiramente, medidas de não geração e redução da geração de resíduos. De acordo com a Lei 12.305/2010, para o gerenciamento correto deve-se observar uma ordem de prioridade, que se inicia com a não geração e termina com a disposição final ambientalmente adequada dos rejeitos, como apresentada na Figura 2:

Figura 2: Hierarquia das ações do manejo de resíduos sólidos

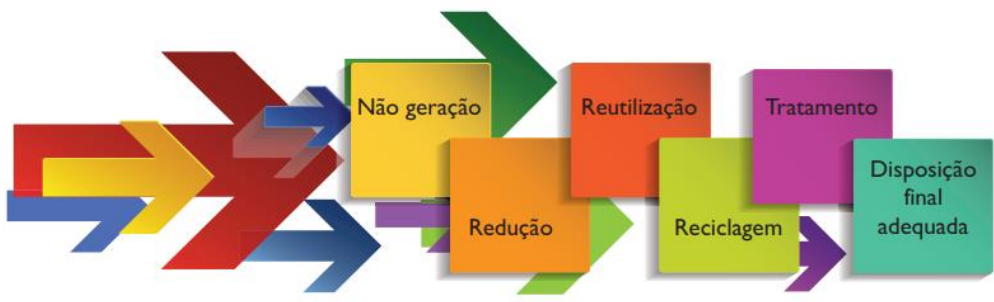

Fonte: Plano de Gerenciamento de Resíduos Sólidos - PGRS: Instrumento de Responsabilidade Socioambiental na Administração Pública (2014). 


\begin{tabular}{cccc} 
A tabela 1 & $\begin{array}{c}\text { apresenta } \\
\text { custos }\end{array}$ um & do & $\begin{array}{c}\text { que no fim do seu ciclo geram resíduos } \\
\text { recicláveis, a fim de obter números reais de } \\
\text { gastos e avaliar uma possível redução deles. }\end{array}$ \\
$\begin{array}{c}\text { levantamento dos } \\
\text { empreendimento, com materiais e produtos }\end{array}$ \\
Tabela 1: Levantamento de custos com papéis e plásticos diversos \\
\hline Material & Quantidade mensal & Custo mensal em reais \\
\hline Papel A4 & 1.000 unidades & 43,80 \\
Papel toalha & 24.000 unidades & 95,40 \\
Copos descartáveis & 500 unidades & 19,75 \\
Sacos de lixo & 50 unidades & 18,98 \\
\hline
\end{tabular}

Fonte: autoria própria.

Mensalmente, o custo total com papéis e plásticos diversos é de aproximadamente 180,00 reais. Se o empreendimento reduzir em, pelo menos, $50 \%$ os seus gastos com esses materiais, a redução do custo anual seria em torno de $1.080,00$ reais. Dessa forma, sugere-se, sempre que possível, utilizar o meio digital para enviar documentos e pagar boletos, realizar o reaproveitamento do papel para anotações e rascunhos, além de impressões frente e verso.

Além disso, a utilização de xícaras, copos ou canecas que possam ser lavadas e reutilizadas também é recomendada, tanto no escritório quanto na área de alimentação dos funcionários, para eliminar ou reduzir consumo de copos descartáveis. Nos banheiros recomenda-se a utilização de porta papel toalhas eficiente, que reduza o consumo do papel utilizado.

$\mathrm{Na}$ pista de abastecimento, onde são gerados os resíduos perigosos, é adequada a utilização de coletores somente para esse fim. É importante ressaltar que no empreendimento, os resíduos são armazenados em conformidade com a NBR
12.235 da Associação Brasileira de Normas Técnicas - ABNT, de 1992 que diz:

Os contêineres e/ou tambores devem
ser armazenados, preferencialmente,
em áreas cobertas, bem ventiladas, e os
recipientes são colocados sobre base
de concreto ou outro material que
impeça a lixiviação e percolação de
substâncias para o solo e águas
subterrâneas. A área deve possuir
ainda um sistema de drenagem e
captação de líquidos contaminados
para que sejam posteriormente
tratados.

As únicas melhorias que devem ser feitas no acondicionamento dos resíduos, dizem respeito à sinalização correta. Os tambores deverão estar sempre sinalizados na cor laranja, que indica que há resíduo perigoso no seu interior, além de estarem devidamente tampados. A utilização de reservatórios sinalizados com cada tipo de resíduo deve estar em conformidade com o código de cores estabelecido pela Resolução 275 do Conselho Nacional do Meio Ambiente - CONAMA de 25 de abril de 2001 (Quadro 2).

Quadro 2: Código de cores para os tipos de resíduos 


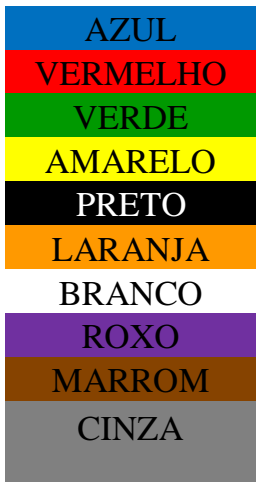

\author{
Papel/papelão \\ Plástico \\ Vidro \\ Metal \\ Madeira
}

Resíduos perigosos

Resíduos ambulatoriais e de serviços de saúde

Resíduos radioativos

Resíduos orgânicos

Resíduo geral não reciclável ou misturado, ou contaminado não passível de separação (Rejeito)

Fonte: Autoria própria, baseada na Resolução CONAMA 275/2001.

Em todas as fontes geradoras citadas, sugere-se adotar recipientes de coleta seletiva, visto que são produzidos tipos diversos de resíduos. O município de São Mateus conta com um Projeto Municipal de Coleta Seletiva, com pontos de entrega voluntária (PEVs) e um galpão para segregação, para onde os catadores de materiais recicláveis direcionam os resíduos. Uma parceria com os catadores do município seria uma medida a ser adotada, já que não geraria custos para o empreendimento, geraria fonte de renda para os catadores e ainda contribuiria para uma redução dos resíduos dispostos no aterro sanitário.

De acordo com Pereira \& Curi (2003), o papel do catador na gestão dos resíduos sólidos deve ser ressaltado, pois ao retirar os materiais recicláveis do meio ambiente, há uma redução da exploração dos recursos naturais, além de retorná-los ao mercado consumidor com menor gasto energético.

Os coletores devem ser fixados nas fontes geradoras de resíduos, como mostra a Figura 3.

Figura 3: Distribuição dos coletores.

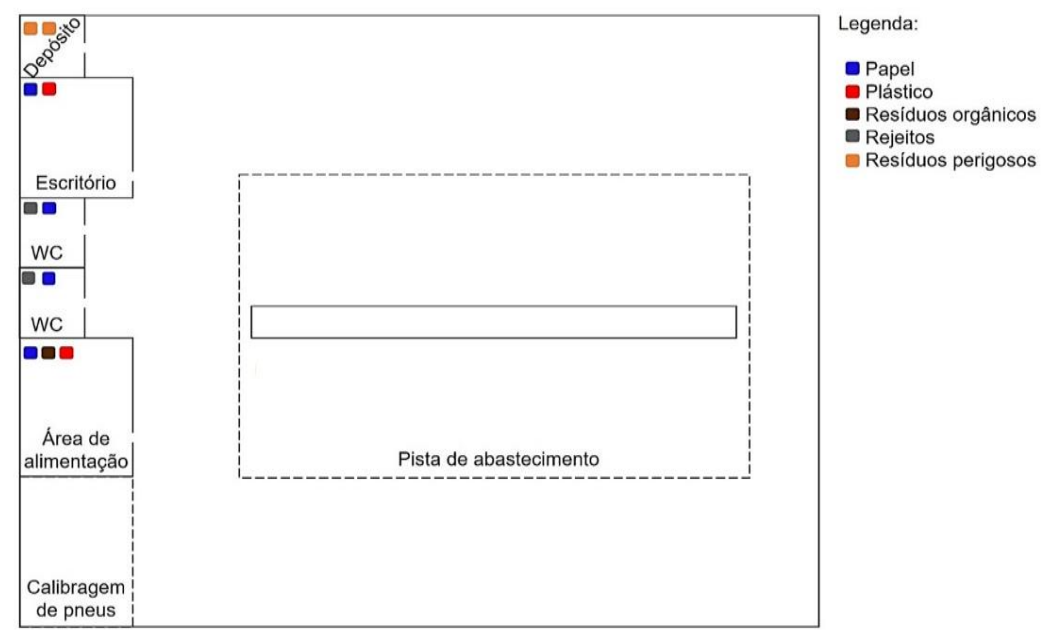

Fonte: Autoria própria.

\subsection{Educação ambiental}

A lei federal $n^{\circ} 9.795$, de 27 de abril de 1999, define Educação Ambiental como:

Os processos por meio dos quais o indivíduo e a coletividade constroem valores sociais, conhecimentos, habilidades, atitudes e competências voltadas para a conservação do meio ambiente, bem de uso comum do povo, essencial à sadia qualidade de vida e sua sustentabilidade. 
Portanto, a adoção do processo de Educação Ambiental no posto é necessária, devido ao fato de que as propostas apresentadas no plano de gerenciamento, dependem diretamente das práticas adotadas por todos os funcionários.

A entrega de folhetos informativos aos funcionários do posto foi realizada (Figura 5), aliada a uma breve explicação acerca da adoção de novas atitudes que contribuam com o gerenciamento correto dos resíduos sólidos, fortalecendo a importância para o meio ambiente. Apesar de algumas práticas de cuidados com os resíduos já serem adotadas no empreendimento, nem todas são executadas corretamente

Figura 5: Folheto informativo de Educação Ambiental

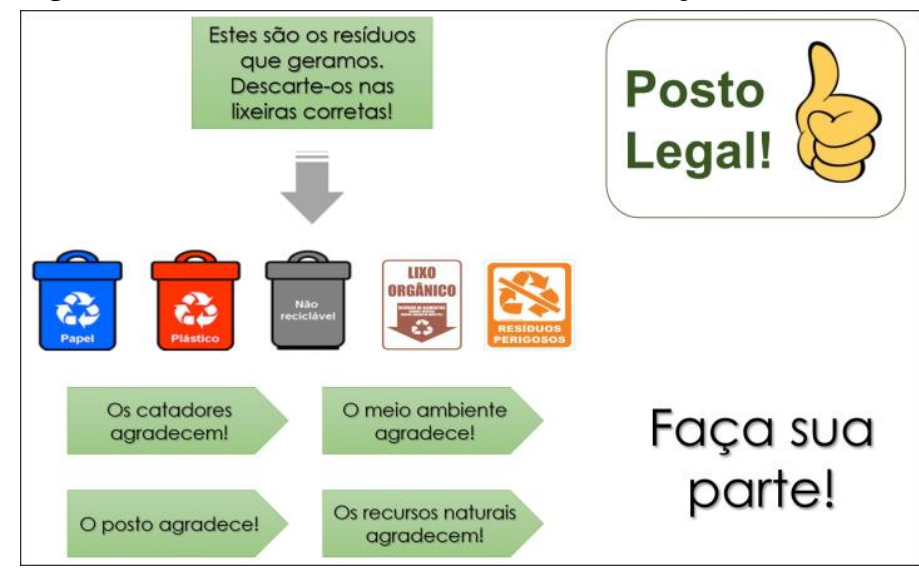

Fonte: Autoria própria.

\section{CONCLUSÃO}

O empreendimento estudado, apesar de adotar medidas de gerenciamento adequado dos resíduos sólidos, ainda possui alguns problemas, como geração em excesso e acondicionamento e segregação incorretos de resíduos.

$\mathrm{O}$ estudo verificou que algumas melhorias precisam ser feitas no empreendimento, como a necessidade de redução do número de impressões, diminuindo o gasto de papel e melhorias no que diz respeito a sinalização correta dos coletores de resíduos perigosos, dentre outras ações. Entende-se, então, que a aplicação do plano de gerenciamento de resíduos sólidos se faz necessária para realizar tais mudanças, evidenciando sua importância.

Para o sucesso do PGRS, a colaboração dos funcionários será de extrema necessidade.

\section{REFERÊNCIAS BIBLIOGRÁFICAS}

ASSOCIAÇÃO BRASILEIRA DE NORMAS TÉCNICAS. NBR 12235: Armazenamento de resíduos sólidos perigosos. Rio de Janeiro, 1992.

\section{ASSOCIAÇÃO BRASILEIRA DE NORMAS TÉCNICAS. NBR 10004: Resíduos sólidos: classificação. Rio de Janeiro, 2004.}

BRASIL. Fundação Nacional de Saúde. Resíduos sólidos e a saúde da comunidade: informações técnicas sobre a interrelação saúde, meio ambiente e resíduos sólidos, Fundação Nacional de Saúde - Funasa, Brasília, DF, 2013.

BRASIL. Lei 9.795, de 27 de abril de 1999. Dispõe sobre a educação ambiental, institui 
a Política Nacional de Educação Ambiental e dá outras providências, Diário Oficial da União, Brasília, DF, 1999.

BRASIL. Lei 12.305 , de 2 de agosto de 2010. Institui a Política Nacional de Resíduos Sólidos; altera a Lei $\mathrm{n}^{\mathrm{0}}$ 9.605, de 12 de fevereiro de 1998; e dá outras providências, Diário Oficial da União, Brasília, DF, 2010.

BRASIL. Ministério do Meio Ambiente. Plano de Gerenciamento de Resíduos Sólidos - Instrumento de Responsabilidade Socioambiental na Administração Pública, Agenda Ambiental na Administração Pública, Brasília, DF, 2014.

BRASIL. Ministério do Meio Ambiente. Resolução CONAMA no 273, de 29 de novembro de 2000. Estabelece diretrizes para o licenciamento ambiental de postos de combustíveis e serviços e dispõe sobre a prevenção e controle da poluição. Diário Oficial da União, 2001.

BRASIL. Ministério do Meio Ambiente. Resolução CONAMA no 275 , de 25 de abril de 2001. Estabelece o código de cores para os diferentes tipos de resíduos, a ser adotado na identificação de coletores e transportadores, bem como nas campanhas informativas para a coleta seletiva. Diário Oficial da União, 2001.

COSTA, Giovani A. da; FERREIRA, Osmar M. Identificação dos resíduos gerados em postos de combustíveis. UCG, Goiás, 2008.

ESPÍRITO SANTO. Lei n ${ }^{\circ}$ 9.264, de 16 de julho de 2009. Institui a Política Estadual de Resíduos Sólidos e dá outras providências correlatas, Diário Oficial dos Poderes do Estado, Vitória, 2009.

GIANNETTI, Biagio F.; ALMEIDA, Cecília M. V. B.; RIBEIRO, Celso M. Avaliação do ciclo de vida (ACV): uma ferramenta importante da ecologia industrial. Revista de graduação de engenharia química, São Paulo, v. 11, p. 13-22, jan. 2003.

GOUVEIA, Nelson. Resíduos sólidos urbanos: impactos socioambientais e perspectiva de manejo sustentável com inclusão social. Revista Ciência \& Saúde Coletiva, Rio de Janeiro, v. 17, n. 6, p. 1503-1510, 2012.

IJSN - INSTITUTO JONES DOS SANTOS NEVES. IBGE, 2010.

LORENZETT, Daniel B.; ROSSATO, Marivane V. A gestão de resíduos em postos de abastecimento de combustível. Revista Gestão Industrial, Ponta Grossa, v. 6, n.2, p. 110-125, abr. 2010.

PEREIRA, Suellen S.; CURI, Rosires C. Modelos de gestão integrada dos resíduos sólidos urbanos: a importância dos catadores de materiais recicláveis no processo de gestão ambiental. Em: LIRA, Waleska Silveira; CÂNDIDO, Gesinaldo Ataíde, Gestão sustentável dos recursos naturais: uma abordagem participativa [online]. Campina Grande: EDUEPB, 21. ed., p. 149-172, 2013. Disponível em: <http://books.scielo.org/id/bxj5n/pdf/lira9788578792824-06.pdf $>$. Acesso em: 15 mar. 2018

SANTOS, Ricardo José S. dos. A Gestão Ambiental em posto revendedor de combustíveis como instrumento de prevenção de passivos ambientais. 2005. 217 f. Dissertação (Mestrado em Sistemas de Gestão) - Universidade Federal Fluminense, Niterói, 2005.

SILVA, Ivana Aparecida F.; CARVALHO, Emília Maria A. Análise diagnóstica sobre a gestão dos resíduos sólidos: um estudo de caso no aterro sanitário de Cuiabá - MT. SEGeT, UFMT, Mato Grosso, 2011. 